JKEP

Vol 3, No 1, Mei 2018

ISSN: 2354-6042 (Print)

ISSN : 2354-6050 (Online)

\title{
Pengaruh Pemberian Ramuan Jahe dan Temulawak terhadap Penurunan Nyeri Haid (Dysmenorea)
}

\author{
Keumalahayati, Nuswatul Khaira, Fazdria \\ Poltekkes Kemenkes Aceh \\ Email : k_mala70@yahoo.coid
}

\begin{abstract}
Artikel history
Dikirim, Sept $10^{\text {th }}, 2018$

Ditinjau, Okt $5^{\text {th }}, 2018$

Diterima, Okt $20^{\text {th }}, 2018$
\end{abstract}

\begin{abstract}
Menstruation is normal in a woman's life. The most common abnormalities are menstrual pain (dysmenorrhoea) and premenstrual syndrome. About one third of menstruating women will feel some pain that accompanies menstruation. The purpose of this study was to determine the effect of the effect of consuming ginger and ginger herbs on decreasing menstrual pain (dysmenorrhoe). The study design was quasiexperimental using the one group pretest-posttest design. The results of the study showed a significant difference in the intensity of menstrual pain before and after the ginger and ginger extract was administered, at a rate of 20: 20 grams compared to a 15: 15 gram dose. This can be seen from the $p$ value obtained at 0,000 ( $p<0.05$ ). The results of the study are expected to expand the area of maternity nursing research for students regarding interventions to reduce menstrual pain in a nonpharmacological manner. For this reason, so that the use of ginger and ginger can be applied in the management of nursing care for women with primary dysmenorrhoea, further research is needed regarding the effectiveness of the management of dysmenorrhoea by utilizing ginger and ginger ingredients so that this action can be used as an alternative intervention.
\end{abstract}

Keywords : Ginger; ginger; menstrual pain.

\begin{abstract}
ABSTRAK
Menstruasi merupakan hal normal dalam kehidupan wanita. Kelainan-kelainan yang paling umum adalah rasa sakit saat menstruasi (dysmenorrhoea) dan sindrom premenstruasi. Sekitar sepertiga wanita menstruasi akan merasakan beberapa rasa sakit yang menyertai menstruasinya. Tujuan penelitian ini untuk mengetahui pengaruh pengaruh mengkonsumsi ramuan jahe dan temulawak terhadap penurunan nyeri haid (dysmenorrhoe). Desain penelitian adalah kuasi eksperimen dengan menggunakan rancangan one group pretest-posttest design. Hasil penelitian perbedaan bermakna penurunan intensitas nyeri haid sebelum dan sesudah diberikan ramuan jahe dan
\end{abstract}


temulawak, dengan takaran $20: 20$ gram dibandingkan dengan takaran $15: 15$ gram. Hal ini terlihat dari nilai $p$ yang diperoleh sebesar $0,000(p<0,05)$. Dari hasil penelitian diharapkan dapat memperluas area penelitian keperawatan maternitas bagi mahasiswa mengenai intervensi mengurangi nyeri haid secara nonfarmakologis. Untuk itu, agar pemanfaatan ramuan jahe dan temulawak dapat diterapkan dalam penatalaksanaan asuhan keperawatan pada wanita dengan dysmenorrhoea primer maka perlu dilakukan penelitian selanjutnya terkait efektivitas penatalaksanaan dysmenorrhoea dengan pemanfaatan ramuan jahe dan temulawak sehingga tindakan ini dapat dijadikan salah satu intervensi alternatif.

Kata Kunci : Jahe; temulawak; nyeri haid

\section{PENDAHULUAN}

Menstruasi merupakan hal normal dalam kehidupan wanita. Menstruasi atau haid adalah perdarahan vagina periodik yang dimulai sekitar 14 hari setelah ovulasi (Bobak, 2005). Menstruasi terjadi akibat terlepasnya mukosa uterus karena tidak terjadi konsepsi. Lama siklus ini sangat bervariasi, tetapi angka rata-rata adalah 28 hari dari permulaan satu periode menstruasi sampai permulaan periode berikutnya (Ganong, 2002). Kebanyakan perempuan mengalami masa menstruasi selama tiga puluh tahun, sejak awal masa remajanya sampai umur 40 atau 50 tahun (Elizabeth, 2005). Secara khusus, wanita mengalami menstruasi pada usia antara 12 dan 13 tahun, tetapi ada yang mengalaminya lebih awal kira-kira usia 10 tahun. Beberapa perempuan mengalami menstruasi usia antara 15 dan 16 tahun (Masland, 1997).

Menstruasi adalah siklus yang kompleks meliputi psikologis, pancaindra, korteks serebri, hipofisis (ovarial aksis), dan endorgan (uterusendometrium, dan alat seks skunder) (Manuaba, 2010). Pada umumnya menstruasi terjadi mengikuti pola yang teratur dan tidak memiliki masalah, namun demikian ada beberapa wanita yang mengalami beberapa kelainan pada saat tertentu. Kelainan-kelainan yang paling umum adalah rasa sakit saat menstruasi (dysmenorrhoea) dan sindrom premenstruasi. Sekitar sepertiga wanita menstruasi akan merasakan beberapa rasa sakit yang menyertai menstruasinya (Elizabeth, 2005 ).

Dysmenorea merupakan rasa nyeri saat menstruasi yang mengganggu kehidupan sehari-hari wanita dan mendorong penderita untuk melakukan pemeriksaan dan konsultasi ke dokter, 
puskesmas atau tenaga kesehatan lainnya (Manuaba, 2010). Dysmenorrhoea dapat menimbulkan gangguan pekerjaan sehari - hari (Manuaba, 2008). Nyeri haid biasanya baru timbul 2 atau 3 tahun sesudah menarche (Liwellyn, 2005). Sedangkan nyeri yang timbul lebih dari 5 tahun setelah menarche seringkali bersifat organik atau dikenal dengan nyeri haid sekunder (dysmenorrhoea secunder) (Price, 2006). Pada kebanyakan wanita yaitu $80 \%$ wanita muda dibawah 25 tahun mengalami nyeri haid (Benson, 2009), nyeri terlokalisasi pada perut bagian bawah dan dapat menjalar ke paha dan pinggang bagian bawah (Hamilton, 2009). Gejala klinik yang timbul pada dysmenorea adalah nyeri abdomen bagian bawah, menjalar ke daerah pinggang dan paha (Manuaba, 2010). Adapun respon sistemik tubuh lain yang timbul bersamaan dengan nyeri haid adalah sakit punggung belakang, lemas dan keletihan, mudah tersinggung, pengeluaran keringat, gejala saluran cerna antara lain kurang nafsu makan (anoreksi), perut kembung, mual, muntah, diare dan gejala sistem saraf pusat seperti pusing, pingsan (sinkop), nyeri kepala dan

konsentrasi buruk (Heitkemper, dkk, Penyebab dysmenorrhea belum diketahui dengan pasti, namun diduga akibat dari pembentukan prostaglandin yang berlebihan, sehingga menyebabkan uterus berkontraksi dengan kuat serta dapat mengakibatkan vasospasme anteriolar. Faktor-faktor psikologis seperti ansietas dan ketegangan juga dapat menunjang dysmenorrhea. Bertambahnya usia seorang wanita, nyeri cenderung menurun dan akhirnya hilang setelah melahirkan anak (Brunner \& Suddarth, 2001). Sampai saat ini belum diketahui dengan jelas bagaimana prostaglandin bisa menyebabkan dismenorea tetapi diketahui bahwa wanita dengan dysmenorea mempunyai prostaglandin yang empat kali lebih tinggi daripada wanita tanpa dysmenorea (Baradero, 2007). 
Nyeri saat haid yang dialami mahasiswi sangat menggangu kenyamanan dan aktivitas sehari-hari di kampus, hal ini tentu akan mengganggu konsentrasi belajar apalagi pada saat ujian dan wanita yang mengalami nyeri haid hanya bisa berbaring di rumah tiap bulan. Untuk mengurangi rasa sakit saat menstruasi karena gangguan primer dapat menggunakan obat penghilang rasa sakit (analgetik) seperti aspirin atau dengan pemberian hormon antiprostaglandin untuk mengurangi kekuatan kontraksi uterus, namun pemberian hormon antiprostaglandin tersebut harus hati-hati terutama pada wanita yang ingin hamil (Hembing, 2008). Selain menimbulkan efek terapi, obat-obatan tersebut juga memiliki efek samping jika dikonsumsi dalam waktu yang lama. Efek samping yang paling sering adalah terjadinya tukak lambung dan pada beberapa orang dapat terjadi gejala hipersensitivitas terhadap aspirin (Ganiswarna, 1995).

Penggunaan obat-obat anti inflamasi nonsteroid dapat memberikan efek samping bila dikonsumsi, oleh karena itu diperlukan suatu cara atau alternatif lain untuk mengatasinya. Dalam hal ini penggunaan bahan alami akan lebih baik dan mengurangi efek samping yang berbahaya bagi kesehatan. Penggunaan bahan alami atau obat tradisional ini sebaiknya memenuhi kriteria mudah didapat, dikenal banyak orang, proses penyimpanannya sederhana, mudah digunakan dan tidak berbahaya dalam penggunaannya (Azwar \& Jacob, 1992). Beberapa bahan alami yang mungkin bisa digunakan adalah jahe dan temulawak. Di Langsa misalnya, berdasarkan pengamatan yang dilakukan peneliti selama ini apabila ada remaja yang mengalami dysmenorea maka orang tuanya sering menganjurkan untuk minum jamu yang berisi temulawak dan ramuan ini dapat menyegarkan tubuh dan mengurangi gangguan menstruasi.

Kandungan aleoresin pada rimpang jahe seperti gingerol, shogaol dan gingeron memiliki aktivitas antioksidan diatas vitamin E (Kumalaningsih, 2006). Menurut British Journal of Obstetrics and Gynaecology (2005), antioksidan dapat membantu seluruh sel dan jaringan tubuh, memperbaiki serta mengatasi peradangan atau inflamasi. Sedangkan pada temulawak, rimpangnya mengandung curcumin yang berfungsi sebagai antiinflamasi 
(antiradang). Selain itu mengandung minyak atsiri yang bermanfaat untuk menghilangkan nyeri (Dalimartha, 2000). Berdasarkan litaratur tersebut ada kemungkinan mengkonsumsi ramuan jahe dan temulawak dapat mengurangi dysmenorrhoea. Hal inilah yang melatarbelakangi peneliti tertarik untuk melakukan penelitian tentang pengaruh pemberian ramuan jahe dan temulawak dalam penatalaksanaan dysmenorrhoea pada Mahasiswi Prodi Keperawatan dan Prodi Kebidanan Kota Langsa. Penelitian ini bertujuan untuk mengidentifikasi penatalaksanaan dysmenorrhoea menggunakan ramuan jahe dan temulawak.

\section{METODE}

Jenis penelitian ini adalah eksperimen dengan rancangan one group pretestposttest design). Penelitian ini membandingkan intensitas nyeri haid sebelum dan sesudah diberi intervensi ramuan jahe dan temulawak dengan takaran $15: 15$ gram dan $20: 20$ gram sebanyak $200 \mathrm{ml}$. Ramuan jahe dan temulawak diberikan kepada responden dengan cara diminum sebanyak $200 \mathrm{ml}$ pada saat responden mengalami nyeri haid.
Populasi dalam penelitian ini adalah semua mahasiswi Program Studi Keperawatan dan Prodi Kebidanan Kota Langsa Poltekkes Kemenkes NAD yang mengalami nyeri haid (dysmenorea). Jika populasi kurang dari 100 maka populasi menjadi sampel penelitian, akan tetapi jika populasi lebih dari 100 maka sampel adalah $25 \%$ dari populasi. Sampel yang diambil dalam penelitian ini adalah 26 orang mahasiswi berdasarkan kriteria-kriteria dari populasi tersebut (Arikunto, 2002).

Instrumen penelitian yang digunakan dalam penelitian ini terdiri dari 2 bagian, yaitu: kuesioner data demografi, dan kuesioner intensitas nyeri. Uji yang digunakan adalah uji statistik paired sample t-test.

Mengingat dampak penelitian ini terhadap subjek penelitian, peneliti dalam hal ini sangat menyadari perannya dan memastikan bahwa penelitian ini tidak hanya menguntungkan bagi diri sendiri, tetapi juga bagi subjek penelitian. Peneliti juga mengantisipasi kemungkinan negatif yang dapat ditimbulkan karena penelitiannya, dan mengambil langkah untuk meminimalkan sekaligus mengatasinya 
(Poerwandari, 2005).

Sebelum melakukan pengumpulan data, peneliti memberikan penjelasan tentang tujuan, dan manfaat penelitian kepada responden dan meminta kesediaan responden untuk berpartisipasi dalam penelitian. Bila bersedia menjadi responden, maka responden tersebut diminta menandatangani surat persetujuan atau informed consent yang sebelumnya telah dibaca oleh responden dan mengerti isi informed consent tersebut. Peneliti benar-benar melindungi hak-hak responden yang menyangkut privasi responden yaitu untuk menjamin kerahasiaan identitas responden dimana pada kuesioner tidak mencantumkan nama responden tetapi hanya memakai inisial.
1. Gambaran Nyeri Haid berdasarkan Karakteristik Demografi Responden Gambaran karakteristik demografi responden ditunjukkan pada tabel 1 . Responden yang berhubungan dengan usia, responden yang mengalami nyeri haid berada pada usia 18 tahun $(19,2$ $\%)$, usia 19 tahun $(7,7 \%)$, usia 20 tahun $(3,8 \%)$, usia 21 tahun $(50,0 \%)$, dan 22 tahun $11,5 \%$ dan usia 23 tahun $(7,7 \%)$. Keseluruhan jumlah responden yang mengalami nyeri haid berada pada usia dibawah 25 tahun. Hasil penelitian ini sesuai dengan pendapat Declan (1997) yang mengatakan bahwa kebanyakan wanita yaitu $80 \%$ wanita muda dibawah 25 tahun mengalami nyeri haid, namun hal tersebut hanya merupakan gejala primer, tanpa implikasi yang serius dan mudah diatasi.

\section{HASIL DAN PEMBAHASAN}

Tabel 1

Gambaran Nyeri Haid berdasarkan Karakteristik Demografi Responden

\begin{tabular}{lcc}
\hline \multicolumn{1}{c}{ Karakteristik Demografi Responden } & \multicolumn{2}{c}{ Responden } \\
\hline Usia & $\mathrm{n}$ & $\%$ \\
18 Tahun & 5 & 19.2 \\
19 Tahun & 2 & 7.7 \\
20 Tahun & 1 & 3.8 \\
21 Tahun & 13 & 50.0 \\
22 Tahun & 3 & 11.5 \\
23 Tahun & 2 & 7.7
\end{tabular}


Suku

Aceh

Batak

Melayu

Jawa

Minang

Siklus Haid

$26-30$ hari

$31-35$ hari
15

1

4

5

1

21

5
57.7

3.8

15.4

19.2

3.8

80.8

19.2
Berdasarkan hasil penelitian karakterisitik demografi responden yang berhubungan dengan suku, sebagian besar responden bersuku Aceh. Mengacu pada teori Potter \& Perry (2005) bahwa keyakinan dan nilai-nilai budaya mempengaruhi cara individu untuk mengatasi nyeri. Individu mempelajari apa yang diharapkan dan apa yang diterima oleh kebudayaan mereka. Hal ini meliputi bagaimana bereaksi terhadap nyeri dan bagaimana seseorang dapat mengekspresikan rasa nyeri tersebut.
2. Intensitas nyeri haid sebelum dan sesudah diberikan ramuan jahe dan temulawak

Penurunan skala intensitas nyeri yang terjadi pada subyek penelitian, yaitu responden yang diberi ramuan jahe dan temulawak dengan takaran 15 gram : 15 gram diperoleh nilai rata-rata (mean) intensitas nyeri haid sebelum intervensi sebesar 5.23 dengan $\mathrm{SD}=1,032$ sedangkan sesudah intervensi $=3,58$ dengan $\mathrm{SD}=1,270$. terjadi penurunan skala nyeri sebesar 1,654, seperti yang terlihat pada tabel 2 .

Tabel 2

Gambaran Intensitas Nyeri Haid dengan Takaran 15 : 15 Gram

\begin{tabular}{cc|cc}
\hline \multicolumn{2}{c}{$\begin{array}{c}\text { Intensitas Nyeri Haid pada Pemberian ramuan jahe dan } \\
\text { temulawak dengan takaran } 15: 15 \text { gram }\end{array}$} \\
\hline \multicolumn{2}{c}{ Sebelum Intervensi } & \multicolumn{2}{c}{ Sesudah Intervensi } \\
\hline Mean & SD & Mean & SD \\
\hline 5,23 & 1,032 & 3,58 & 1,270 \\
\hline
\end{tabular}


Pada pemberian jahe dan temulawak dengan takaran 20:20 gram di peroleh nilai rata - rata (mean) intensitas nyeri haid sebelum intervensi sebesar 5.62 dengan $\mathrm{SD}=1.061$ sedangkan sesudah intervensi $=1.69$ dengan $\mathrm{SD}=0,970$, terjadi penurunan skala nyeri sebesar 3,923, seperti yang terlihat pada tabel 3 .

Tabel 3

Gambaran Intensitas Nyeri Haid Takaran 20 : 20 gram

\begin{tabular}{cc|cc}
\hline \multicolumn{3}{c}{$\begin{array}{c}\text { Intensitas Nyeri Haid pada Pemberian ramuan jahe dan } \\
\text { temulawak dengan takaran 20 : 20 gram }\end{array}$} \\
\hline \multicolumn{2}{c}{ Sebelum Intervensi } & \multicolumn{2}{c}{ Sesudah Intervensi } \\
\hline Mean & SD & Mean & SD \\
\hline 5,62 & 1,061 & 1,69 & 0,970 \\
\hline
\end{tabular}

Berdasarkan hasil penelitian tingkatan nyeri haid yang dialami responden di mulai dari tingkat nyeri haid sedang dan nyeri haid berat. Skala intensitas nyeri haid bervariasi mulai dari skala 4 sampai dengan skala 8. Dalam penelitian ini terdapat subyek yang mengalami penurunan intensitas nyeri sangat bermakna yaitu pemberian ramuan jahe dan temulawak dengan takaran $20: 20$ gram (dari skala 7 menjadi 2 sebanyak 1 orang, skala 5 menjadi 1 sebanyak 1 orang, skala 6 menjadi 2 sebanyak 5 orang, dan skala 5 menjadi 1 sebanyak 4 orang). Sedangkan subyek yang mengalami penurunan intensitas kurang bermakna yakni dari skala 6 menjadi 4, dan skala 5 ke 2 masing-masing sebanyak 1 orang. Kemudian subyek yang mengalami penurunan intensitas nyeri bermakna pada pemberian ramuan jahe dan temulawak dengan takaran $20: 20$ gram (dari skala 7 menjadi 5 sebanyak 1 orang, skala 6 menjadi 3 sebanyak 1 orang).

Perbedaan tinggi rendahnya skala intensitas nyeri haid yang dirasakan seseorang tidak Hasil penelitian ini sejalan dengan pernyataan dari Mahon (1994), yang mengatakan bahwa nyeri bersifat subyektif dan sangat bersifat individual dan berbeda pada setiap individu. Tingkat nyeri ini juga dapat dipengaruhi oleh berbagai faktor antara lain faktor psikis dimana nyeri dapat dibangkitkan atau diperberat oleh 
keadaan psikis penderita. Bagi wanita yang secara emosional tidak stabil, dan tidak mendapat penjelasan yang baik tentang proses haid dan cara mengatasi nyeri haidnya akan mudah timbul nyeri haid. Selain itu nyeri juga dapat disebabkan oleh faktor konstitusi, alergi, neurologis, vasopressin, faktor hormonal dan prostaglandin.

Pada penelitian ini semua faktor yang dianggap berkontribusi terhadap nyeri diabaikan. Untuk meminimalkan adanya pengaruh perlakuan yang lain terhadap pemberian ramuan jahe dan temulawak maka dianjurkan bagi semua responden untuk tidak melakukan tindakan apapun seperti mengoleskan minyak kayu putih, balsem, minum air hangat, membuat posisi tubuh seperti meringkuk atau menungging dan juga mengkonsumsi obat-obatan penurun nyeri selama menjadi responden dalam penelitian ini. Dimana hal tersebut dapat berpengaruh terhadap penurunan nyeri haid dan membiaskan hasil penelitian.

Pernyataan diatas mendukung pendapat dari Kumalaningsih (2006) bahwa kandungan aleoresin pada rimpang jahe seperti gingerol, shogaol dan gingeron memiliki aktivitas antioksidan diatas vitamin E. Antioksi dan dapat membantu seluruh sel dan jaringan tubuh memperbaiki serta mengatasi peradangan atau inflamasi. British Journal of Obstetrics and Gynaecology (2005) mengatakan bahwa vitamin E dapat mengurangi keparahan dan durasi periode sakit serta kehilangan darah menstruasi yang cukup banyak. Sedangkan kandungan kimia pada rimpang temulawak yang berasal dari fraksi kurkuminoid mengandung kurkumin yang mempunyai aktivitas antiradang (antiinflamasi) dan desmetoksikurkumin (Dalimartha, 2000). Oleh karena kandungan dari jahe dan temulawak tersebut sehingga ramuan jahe dan temulawak dapat mengurangi dysmenorrhoea yang dirasakan oleh mahasiswi.

\section{Perbedaan Intensitas Nyeri Haid} Sebelum dan Sesudah Intervensi Perbedaan intensitas nyeri haid sebelum dan sesudah diberikan ramuan jahe dan temulawak dengan takaran $15: 15$ gram dengan 20 : 20 gram, dianalisis paired t-test. Pada tabel 4 terlihat perbedaan nilai rata-rata antara pengukuran sebelum dan sesudah intervensi pada takaran 15 : 15 gram adalah 1,645. 
Hasil perbedaan nilai rata-rata antara pengukuran sebelum dan sesudah intervensi pada takaran $20: 20$ adalah 3,923. Perbedaan ini didukung oleh nilai $\mathrm{p}$-value $=0,000(<\alpha=0,05)$, yang berarti ada perbedaan nilai rata-rata antara pengukuran sebelum dan sesudah intervensi pemberian ramuan jahe dan

temulawak baik pada takaran $15: 15$ gram maupun $20: 20$ gram. Tabel 4 juga memperluhatkan bahwa ramuan jahe dan temulawak dengan takaran 20 : 20 gram lebih berpengaruh terhadap penurunan intensitas nyeri haid dibandingkan dengan takaran $15: 15$ gram.

Tabel 4

Perbedaan Intensitas Nyeri Haid Sebelum dan Sesudah Intervensi dengan Uji Paired T-Test

\begin{tabular}{lccc}
\hline & Mean df & T & p-value \\
\hline Pre - Postest takaran 15 : 15 gram & 1,654 & 10,579 & 0,000 \\
Pre - Posttest takaran 20 : 20gram & 3,923 & 26,879 & 0,000 \\
\hline
\end{tabular}

Hasil penelitian dari Hairani (2008) yang melakukan intervensi penurunan dengan kompres panas, diperoleh hasil rata-rata penurunan nyeri pada kelompok intervensi nas sebesar 3,32 (dengan menggunakan skala pengukuran nyeri Numerical Rating Scale dengan skala 0-10). Sementara pada penelitian ini rata-rata penurunan nyeri pada kelompok intervensi yang diberi ramuan jahe dan temulawak dengan takaran 15 - 15 gram sebesar 1,654, sedangkan dengan takaran 20 : 20 gram sebesar 3,923 (dengan menggunakan skala pengukuran nyeri Numerical Rating Scale dengan skala 010). Dengan demikian hasil penelitian ini membuktikan bahwa ramuan jahe dan temulawak dapat berpengaruh terhadap penurunan nyeri haid.

\section{SIMPULAN}

Berdasarkan hasil penelitian maka diambil kesimpulan terdapat perbedaan yang signifikan terhadap penurunan intensitas nyeri haid setelah diberi intervensi ramuan jahe dan temulawak dengan takaran 15: 15 gram dan takaran 20 : 20 gram. Dengan demikian dapat disimpulkan bahwa ramuan jahe dan temulawak dapat digunakan dalam penatalaksanaan dysmenorrhoea primer pada mahasiswi Program Studi Keperawatan dan Program Studi 
Kebidanan Kota Langsa Poltekkes kepmenkes NAD.

Hasil penelitian juga meberikan rekomendasi untuk intervensi mengurangi nyeri haid secara nonfarmakologis. Pembahasan mengenai nyeri haid dan penatalaksanaannya dapat diintegrasikan secara lebih meluas khususnya dapat ditambahkan dalam topik kesehatan reproduksi wanita dan permasalahannya serta penatalaksanaan yang tepat diberikan oleh tenaga kesehatan. Bagi praktek keperawatan, pemanfaatan ramuan jahe dan temulawak dapat diterapkan dalam penatalaksanaan asuhan keperawatan pada wanita dengan dysmenorrhoea primer. Terkait efektivitas penatalaksanaan dysmenorrhoea dengan pemanfaatan ramuan jahe dan temulawak, maka perlu dilakukan penelitian lebih lanjut.

\section{UCAPAN TERIMAKASIH}

Terimakasih peneliti ucapkan kepada berbagai pihak yang telah memberikan bantuan pada penelitian yang dilakukan yaitu kepada Tim Reviewer, Ketua Prodi Keperawatan Langsa, Ketua Prodi Kebidanan Langsa, Seluruh Dosen dan
Staf Prodi Keperawatan dan Kebidanan Langsa serta seluruh pihak-pihak terkait lainnya.

\section{DAFTAR RUJUKAN}

Azwar \& Jacob. 1992. Antropologi Kesehatan Indonesia, Jilid 1 "Pengobatan Tradisional". Jakarta: EGC.

Baradero, Mary, dkk. 2007. Asuha Keperawatan Klien dengan gangguan sistem reproduksi dan seksualitas, Edisi 1. Jakarta: EGC.

Benson and Pernoll's. 2008. Buku saku Obstetri dan Ginekologi, Edisi. 9, Jakarta, EGC.

Bobak, dkk. 2005. Buku Ajar Keperawatan Maternitas. Ed. 4. Jakarta: EGC.

Brunner \& Suddarth. 2001. Buku Ajar Keperawatan Medikal Bedah. Vol 1. Jakarta: EGC.

Dalimartha, S. 2000. Atlas Tumbuhan Obat Indonesia. Jilid 2. Jakarta: Trubus Agriwidya.

Elizabeth, O. 2005. Panduan Kesehatan bagi Wanita. Jakarta: Prestasi Pustaka Publisher.

Ganong, W F. 2002. Buku Ajar Fisiologi Kedokteran. Ed. 20. Jakarta: EGC.

Hamilton Carole. 2009. Obstetri dan Ginekologi. Edisi. 2. Jakarta. EGC.

Kumalaningsih, S. 2006. Antioksidan Alami. Cet.1. Surabaya: Trubus Agrisarana. 
Llewellyn, D. 2005. Setiap Wanita. Jakarta: Delapratasa Publishing.

Manuaba, dkk. 2010. Buku Ajar Ginekologi. Penerbit EGC Jakarta.

Nursalam. 2003. Konsep \& Penerapan Metodologi Penelitian Ilmu Keperawatan. Jakarta: Salemba Medika.
Price S.A. 2006. Patofisiologi Konsep klinis proses-proses Penyakit. Edisi. 6. Jakarta. EGC.

Smeltzer, S. C. 2001. Buku Ajar Keperawatan Medikal Bedah Brunner \& Suddath/editor, Suzanne C. Smeltzer, Brenda G. Bare; alih bahasa, Agung Waluyo, (et.al); editor edisi bahasa Indonesia, Monica Ester, Ellen Panggabean. ( $8^{\text {th }}$ ed). Jakarta: EGC 